Artigo

\title{
Formação de professores de matemática em projeto de extensão: percepções docentes em tempos da pandemia da COVID-19
}

\section{Training of mathematics teachers in an extension project: teaching perceptions in times of the COVID-19 pandemic}

\author{
Formación de profesores de matemáticas en un proyecto de extensión: percepciones \\ pedagógicas en tiempos de la pandemia COVID-19
}

\author{
Rosana Maria Luvezute Kripka ${ }^{1}$ \\ iD [0000-0002-8493-6900] \\ Paula Boito ${ }^{2}$ \\ [0000-0002-2410-6286] \\ Juliana Valério ${ }^{3}$ \\ [0000-0002-9576-9319]
}

\begin{abstract}
Resumo
Apresentam-se percepções sobre participações docentes em ações de um projeto de extensão para a formação inicial e continuada de professores de matemática da educação básica, realizado ao longo de 2019 e durante a pandemia da COVID-19, em 2020. São descritos aspectos metodológicos adotados e, por meio da abordagem qualitativa, percepções dos participantes sobre: relevância de suas participações; aspectos positivos e negativos; e sugestões para melhoria da qualificação do processo formativo. Também são apresentadas percepções relacionadas ao processo de formação em tempos da pandemia. Concluiu-se que, apesar da necessidade de mudança/adequação para a modalidade remota, os objetivos do projeto de formação continuada foram atingidos. Os professores perceberam todos os aspectos relacionados aos pressupostos adotados da investigação-ação, o que indica que a proposta continuou sendo viável. Também se constatou a percepção de que suas participações os ajudaram no processo de transição, pois houve a socialização e troca de saberes, tanto sobre conhecimentos matemáticos e pedagógicos, como sobre possibilidades de abordagens alternativas, com o uso de recursos tecnológicos digitais. Nas percepções sobre a experiência em 2020, um aspecto positivo que se destacou foi a realização de encontros online, favorecendo constituição de um grupo maior de professores. E um aspecto negativo relevante foi que os acadêmicos não tiveram a oportunidade de desenvolver seus saberes práticos, devido a impossibilidade de estarem em sala de aula presencial. Também apareceram percepções de que o projeto de extensão possibilitou aproximar a Universidade dos professores da Educação Básica e, ainda, permitiu a integração entre ações de ensino, pesquisa e extensão.
\end{abstract}

\footnotetext{
${ }^{1}$ rkripka@upf.br, Doutora em Educação em Ciências e Matemática, Professora do magistério superior do Curso e da Área da Matemática, Universidade de Passo Fundo (UPF), Passo Fundo/ RS/BR.

2 paulaboito@upf.br, Mestre em Ensino de Ciências e Matemática, Doutoranda do Programa de Pós-Graduação em Ensino de Ciências e Matemática (PPGECM/UPF) e Bolsista de Extensão, Universidade de Passo Fundo (UPF), Passo Fundo/ RS/BR.

${ }^{3}$ ju.valerio@hotmail.com, Licencianda em Matemática pela Universidade de Passo Fundo (UPF), Bolsista de Extensão, Universidade de Passo Fundo (UPF), Passo Fundo/ RS/BR.
} 
Palavras-chave: Formação Continuada. Matemática. Projeto de Extensão. Investigação-Ação. COVID19.

\begin{abstract}
Perceptions about teaching participation in actions of an extension project for the initial and continuing training of basic education mathematics teachers, done throughout the years of 2019 and during the pandemic of COVID-19 in 2020, are presented. The methodological aspects adopted are described and, through the qualitative approach, participants' perceptions about: relevance of their participation; positive and negative aspects; and suggestions for improving the qualification of the training process. Perceptions related to the formation process in times of the pandemic are also presented. It was concluded that, despite of the need to change / adapt to the remote modality, the objectives of the continuing education project were achieved. The teachers perceived all aspects related to the assumptions adopted in the action investigation, which indicates that the proposal remained viable. There was also a perception that their participation helped them in the transition process, as there was socialization and exchange of knowledge, both on mathematical and pedagogical fields, as well as on the possibilities of alternative approaches alongside the usage of digital technological resources. In the perceptions about the experience developed in 2020, a positive aspect that stood out was the holding of online meetings, favoring the constitution of a larger group of teachers. And a relevant negative aspect was that the academics did not have the opportunity to develop their practical knowledge, due to the impossibility of being in the classroom. Perceptions which also appeared were that the extension project made it possible to bring the University closer to the teachers of Basic Education and also allowed the integration between actions on teaching, research and extension.
\end{abstract}

Keywords: Teacher training. Mathematics. Extension project. Action-Research. COVID-19.

\title{
Resumen
}

Se presentan percepciones sobre la participación docente en acciones de un proyecto de extensión para la formación inicial y continua de profesores de matemáticas de educación básica, , realizado a lo largo de 2019 y durante la pandemia COVID-19 en 2020. Se presentan los aspectos metodológicos adoptados $y$, a través del enfoque cualitativo, las percepciones de los participantes sobre: relevancia de su participación; aspectos positivos y negativos; y sugerencias para mejorar la calificación del proceso de formación. También se presentan percepciones relacionadas con el proceso de formación en tiempos de pandemia. Se concluyó que, a pesar de la necesidad de cambiar / adaptarse a la modalidad remota, se lograron los objetivos del proyecto de educación continua. Los docentes percibieron todos los aspectos relacionados con los supuestos adoptados en la investigación de la acción, lo que indica que la propuesta se mantuvo viable. También se percibió que su participación les ayudó en el proceso de transición, ya que hubo socialización e intercambio de conocimientos, tanto sobre conocimientos matemáticos y pedagógicos, como sobre las posibilidades de enfoques alternativos, con el uso de recursos tecnológicos digitales. En las percepciones sobre la experiencia en 2020, un aspecto positivo que se destacó fue la realización de encuentros online, favoreciendo la constitución de un grupo mayor de docentes. $Y$ un aspecto negativo relevante fue que los académicos no tuvieron la oportunidad de desarrollar sus conocimientos prácticos, debido a la imposibilidad de estar en el aula. También aparecieron percepciones de que el proyecto de extensión permitió acercar la Universidad a los docentes de Educación Básica y también permitió la integración entre acciones de docencia, investigación y extensión.

Palabras claves: Educación Continuada. Matemáticas. Proyecto de Extensión. Investigación para la Acción. COVID-19. 


\section{Introdução}

A formação continuada de professores é um processo necessário ao docente que busca a atualização e o aprimoramento de seus saberes para o exercício pleno de sua profissão no cotidiano da escola em que atua.

Nóvoa (2017) destaca que entre 1987 e 1992, nos processos de formação de professores a abordagem foi marcada pela "universalização" da formação docente e pelas ideias de "professor reflexivo" e de "professor pesquisador". Além disso, ao se referir à necessidade contemporânea de profissionalização do saber docente indica que é necessário que nesses processos sejam valorizados os seguintes aspectos: disposição pessoal (para aprender a ser um professor); interposição profissional (como aprender a se sentir um professor), composição pedagógica (como aprender a agir como um professor), recomposição investigativa (como aprender a conhecer como um professor) e exposição pública (como aprender a intervir como um professor).

Além disso, devido às características do trabalho docente, verifica-se que se trata de um forte aliado aos processos de pesquisa-ação, também conhecidos como processos de investigação-ação. Nesses, os professores ao participarem colaborativamente do desenvolvimento de projetos de pesquisa, elaborados a partir de suas necessidades e realidades, podem compreender melhor os fenômenos/problemas a serem estudados e podem trazer uma maior contribuição para os processos de ensino e de aprendizagem nos quais estão inseridos (MOLINA, 2007).

$\mathrm{Na}$ investigação-ação, com foco para a formação de professores, valoriza-se a imersão reflexiva consciente do professor em sua prática, partindo-se da investigação sobre temas gerados pela própria experiencia cotidiana, tendo em vista o aprimoramento e a aprendizagem profissional, de modo a ressignificar a própria profissão docente. Ao possibilitar a ação, com a reflexão sobre essa ação, transforma o trabalho docente em pesquisa e possibilita o desenvolvimento da autonomia, da criatividade, da valorização profissional e da experimentação de soluções próprias para os problemas vivenciados (MOLINA, 2007).

Destaca-se que a metodologia da investigação-ação, que também pode ser desenvolvida por meio de projetos de extensão, por possibilitar a aproximação da universidade do dia-a-dia da escola, permite que sejam identificados novos caminhos na busca de uma educação de qualidade para todos.

Nessa perspectiva, desde 2017 vem sendo desenvolvido o projeto de extensão "Formação Continuada de Professores de Matemática" (PFCPMat), na Universidade de Passo Fundo (UPF), vinculado ao curso de Licenciatura em Matemática da UPF. Do projeto participam colaborativamente professores que atuam na educação básica, acadêmicos extensionistas da UPF e professores de extensão da própria Universidade.

O principal objetivo do projeto é desenvolver ações, por meio da proposta da investigação-ação, as quais possibilitam a formação continuada de professores que atuam na educação básica. Em paralelo a esse processo, como propicia o compartilhamento e aprimoramento de saberes docentes dos professores, que atuam na educação básica ou no ensino superior, também colabora com a formação inicial dos estudantes de Licenciatura em Matemática, os quais participam dos encontros formativos como bolsistas extensionistas.

Até 2019, as ações do projeto eram desenvolvidas de modo presencial e em 2020, devido à pandemia do COVID-19, as ações passaram a ser realizadas por meio de encontros virtuais. 
Devido às mudanças necessárias em relação ao ensino, que deixou de ser presencial e passou a ser oferecido de modo remoto, em momentos síncronos e assíncronos, as necessidades e dificuldades dos professores nesse período também mudaram.

Como alguns professores participantes e estudantes participaram nas duas modalidades de execução das ações do projeto de extensão PFCPMat, buscou-se por meio de uma pesquisa com abordagem qualitativa identificar percepções relacionadas ao processo de formação continuada oferecido antes e durante o período da pandemia da COVID-19.

A seguir são apresentados os procedimentos metodológicos adotados na pesquisa e no projeto, para o qual se faz a descrição de ações realizadas em 2019 (antes da pandemia) e em 2020 (durante a pandemia) e mudanças/adaptações que foram necessárias. Na sequência são apresentadas as percepções dos participantes nos dois momentos, sendo que para o último período se destacam suas percepções em relação à seguinte pergunta: "De modo geral, como você percebe as experiências e sentidos da "não presença" no ensino e na aprendizagem da matemática em tempos da pandemia da COVID-19?"

\section{Procedimentos metodológicos}

O presente trabalho caracteriza-se pela abordagem da pesquisa qualitativa na medida em que visa identificar e compreender aspectos relevantes sobre os processos de formação de professores vivenciados em 2019 e 2020, antes e durante o período da pandemia da COVID-19, tendo em vista compreender percepções dos participantes relacionadas com a temática (MINAYO, 2008).

Os participantes da pesquisa são sete professores da Educação Básica que fazem parte do processo de formação continuada, o qual é propiciado por meio da realização de um projeto de extensão da Universidade de Passo Fundo, RS, BR.

Tendo em vista identificar as percepções dos professores na participação do projeto, em período anterior e posterior à pandemia da COVID-19, foram aplicados questionários aos professores participantes, constituídos de três perguntas abertas iguais nos dois anos de 2019 e 2020, que se referiam aos aspectos mais gerais sobre suas compreensões sobre a proposta de formação continuada, e mais duas perguntas específicas que se referiram às percepções de mudanças e implicações devidas à pandemia da COVID-19.

Em 2019, dentre os professores participantes, apenas quatro deles responderam ao questionário, sendo que dois atuavam no ensino fundamental e dois no ensino médio. No ano de 2020, apenas cinco responderam ao questionário sendo que, nesse caso, dois deles atuavam no ensino fundamental e quatro deles atuavam no ensino médio (uma das professoras atuava nos dois níveis).

\section{Fundamentação teórica do Projeto de Formação Continuada}

As ações do projeto são desenvolvidas conforme as etapas da Investigação-Ação apresentados por Ponte (1998, p. 9):

- Caraterização da situação-problema.

- Conceber um plano de trabalho, definindo ações a serem realizadas.

- Executar o plano e fazer ajustes, quando necessário. 
- Refletir sobre o trabalho executado (sobre o processo e sobre o produto) e identificar novas questões para investigação.

Segundo Ponte (1998, p. 9):

Numa investigação ou numa investigação-aç̧ão é preciso começar por caracterizar muito bem o problema ou a situação-problema que queremos resolver. Depois, é preciso conceber um plano de trabalho, definindo quais as actividades a realizar, os instrumentos a utilizar, o calendário a seguir, os recursos a mobilizar, o papel dos diversos intervenientes no trabalho. Seguese a fase de execução do plano, corrigindo a trajectória quando necessário. Finalmente há que avaliar o alcance do trabalho realizado, reflectindo sobre o processo e o produto, e identificar novas questões para investigação.

A proposta da formação continuada na perspectiva da investigação-ação visa possibilitar o desenvolvimento profissional e a geração de novos conhecimentos por meio da reflexão sobre a prática, tendo em vista a intencionalidade e sistematização das reflexões, realizadas por meio da ação. Segundo Anderson e Herr (2016, p. 6):

[...] A investigação-ação requer uma espiral de ciclos de planejamento, ação, observação e reflexão. Os resultados de um ciclo de investigação servem como ponto de partida para o seguinte, e o conhecimento produzido é relevante para a resolução de problemas locais e a aprendizagem profissional dos docentes/investigadores.

Nessa abordagem destaca-se inicialmente que a definição do tema a ser trabalhado é realizada pelo grupo, de acordo com as necessidades indicadas pelos professores, que se destacam nos contextos das escolas nas quais atuam. A partir da situação-problema identificada, por meio de imersões reflexivas e do trabalho colaborativo, se propõe o desenvolvimento de ações, dos instrumentos a serem utilizados; do calendário a serem seguido, dos recursos a serem mobilizados e também se define os papéis dos participantes na intervenção prática.

Assim, busca-se propiciar a formação dos professores de matemática a partir de seus próprios contextos escolares de atuação, de modo que ao investigarem reflexivamente sobre ações envolvendo práticas, elaboradas a partir de problemas da sua realidade, os professores possam aprofundarem seus conhecimentos teóricos e práticos, tendo em vista o aprimoramento e capacitação para suas atuações na profissão como docente.

Destaca-se que a proposta metodológica se aproxima dos sentidos propostos por Mizukami et.al (2002) no que se refere à pressupostos da pesquisa-ação colaborativa no que tange à: construção do conhecimento sobre a aprendizagem e o desenvolvimento da docência e a melhoria da prática. Segundo a autora:

Aprender a ser professor, nesse contexto, não é, portanto, tarefa que se conclua após estudos de um aparato de conteúdo e técnica de transmissão deles. É uma aprendizagem que deve se dar por meio de situações práticas que sejam efetivamente problemáticas, o que exige o desenvolvimento de uma prática reflexiva competente. Exige ainda que, além de conhecimentos, sejam trabalhadas atitudes, as quais são consideradas tão importantes quanto os conhecimentos. (MIZUKAMI et al., 2002, p. 12). 
A seguir, são apresentadas características gerais das ações realizadas em 2019 e, a seguir as mudanças/adequações realizadas devido ao distanciamento imposto pela pandemia da COVID-19.

\section{Descrição das ações realizadas até 2019}

Desde 2017 até 2019, o Projeto de Formação Continuada de Professores de Matemática (PFCPMat) da UPF foi proposto e desenvolvido de forma presencial.

Foram previstas e realizadas reuniões, no âmbito da UPF, onde os professores da educação básica, que atuam na cidade de Passo Fundo, encontravam-se com os professores universitários (orientadores extensionistas) e acadêmicos bolsistas extensionistas, da UPF, para definição do tema e realização dos planejamentos de ações.

Assim, conforme a necessidade dos professores, nesses encontros eram produzidos sequenciamentos didático-pedagógicos, os quais emergiam de reflexões sobre o tema escolhido. Nesse processo, de elaboração colaborativa, as compreensões e saberes eram compartilhados e eram discutidas quais alternativas pedagógicas o grupo julgava mais adequadas ao contexto.

Os conteúdos abordados nas sequências didáticas elaboradas foram escolhidos pelos grupos, de acordo com as sugestões dos professores participantes, visando uma construção ou reconstrução de conceitos com significados. Os temas escolhidos em 2019 tiveram como objetivo contemplar o estudo de frações no sexto ano do ensino fundamental e o estudo de estatística, para o no ensino médio, explorando o tema "Estatística e Sustentabilidade".

Destaca-se que, após as elaborações das sequências didáticas, os professores das escolas fizeram suas aplicações em sala de aula presencial. Além disso, que as propostas eram revistas quando o professor, refletindo sobre a sua ação, percebia que algo no sequenciamento não ocorria conforme o esperado. As questões eram socializadas nos encontros de formação e se faziam as alterações que o grupo julgava necessárias.

Durante a aplicação das sequências, alguns acadêmicos tiveram a oportunidade de irem até as escolas para acompanharem a execução das tarefas criadas pelo grupo. Ao observarem a prática docente, auxiliando o professor no desenvolvimento da proposta e no esclarecimento de dúvidas individuais dos alunos, também tiveram oportunidade de aprender por meio da experiência com a prática, o que os possibilitou o desenvolvimento de saberes práticos, ocorridos em sala de aula.

Em paralelo à essa ação, também foi proposto o desenvolvimento e execução de oficinas, pelos acadêmicos extensionistas (com a orientação/supervisão dos professores extensionistas da UPF), de modo que os futuros professores pudessem atender presencialmente algumas aulas de turmas dos professores do ensino básico, participantes do projeto. A ideia, dessa ação, consistia em propiciar momentos de formação inicial para os acadêmicos relacionada à construção de saberes práticos e, também, viabilizar a participação dos professores das escolas nas reuniões formativas.

Destaca-se que os temas das oficinas foram definidos conforme os assuntos abordados pelos professores em suas salas de aula, tendo em vista complementar e reforçar a compreensão dos estudantes sobre tais conteúdos. As propostas das oficinas, geralmente, envolviam abordagens alternativas com tarefas, ou jogos, de modo a despertar o interesse pela aprendizagem de conceitos e estimular a participação ativa dos estudantes nas aulas. Além disso, também foram solicitadas aos acadêmicos extensionistas que planejassem 
algumas oficinas mais elaboradas, com temas variados, as quais foram oferecidas para alunos de outras turmas de outros professores (os quais não participavam do processo de formação continuada). Nesses casos, os estudantes geralmente se deslocavam até a UPF com objetivo de usar computadores ou materiais manipuláveis, oferecidos pelo laboratório de matemática, de modo a terem um dia diferente de aprendizagem.

Devido ao fato de as reuniões formativas ocorrerem nos mesmos períodos nos quais eram oferecidas as oficinas, os acadêmicos extensionistas ora participavam do planejamento das sequências didáticas, elaboradas pelos professores no âmbito da Universidade, e ora participavam das oficinas realizadas com os alunos no âmbito das escolas. Isso dificultou que os acadêmicos acompanhassem todo o processo de formação continuada proposto aos professores, que ocorriam nas reuniões formativas, nas quais eram propiciados momentos de reflexão sobre as práticas vivenciadas e de compartilhamento de ideias na proposição das sequências didáticas elaboradas.

\section{Continuidades e mudanças/adaptações no contexto da pandemia em 2020}

No ano de 2020, devido à pandemia da COVID-19, houve a necessidade de algumas mudanças no projeto, para dar prosseguimento ao trabalho. As reuniões presenciais não poderiam mais acontecer por causa do distanciamento social.

Desta forma, como alternativa aos encontros na UPF e à execução das atividades na escola, optamos por marcar reuniões semanais de forma remota, utilizando como ferramenta - Google Meet. Assim foi possível reunir acadêmicos, orientadores e professores para o mesmo momento de formação. Nestes encontros, foram definidos (conforme sugestão dos professores) temas para o sequenciamento didático, planejamento do sequenciamento de forma colaborativa, a execução em sala de aula virtual pelos professores regentes de classe, enquanto os acadêmicos bolsistas atuaram no suporte a esses professores. Também foi planejado, que após a aplicação do sequenciamento com as turmas, a análise dos dados gerados, tendo em vista a reflexão sobre as ações e a identificação de novas questões investigativas.

O objetivo principal do projeto, que consiste na formação continuada de professores da educação básica. Porém, a metodologia de trabalho com os estudantes nas escolas, por sua vez, teve que ser adaptada para as aulas remotas, tanto aquelas ocorridas de maneira síncrona, quanto às assíncronas, com planejamento de atividades como vídeos, jogos e materiais que possibilitassem abordagem dos conceitos matemáticos envolvidos, conforme o tema escolhido.

Quanto aos acadêmicos em formação inicial, apesar de ter ficado prejudicado o aprimoramento do conhecimento prático, vivenciado em sala de aula, houve um aprofundamento na relação teórica e de planejamento de ações, que fazem parte da proposta de formação propiciada aos professores. Puderam participar ativamente e acompanhar cada etapa, seja pelas leituras indicadas, pelas discussões sobre a prática, com relatos da experiência dos professores que já atuam na educação básica, criação de materiais usados como recursos pedagógicos, elaboração de vídeos e material para avaliação. 


\section{Análise de dados e resultados}

Na sequência do texto, destaca-se que as falas dos participantes estão apresentadas em itálico, para que se possa dar destaque aos seus argumentos e para que se possa diferenciá-las das citações dos autores.

As respostas dos professores também foram codificadas, de modo que as identidades dos participantes fossem preservadas. Como exemplo, o código (P2.1.2019) refere-se ao professor 2, reposta à pergunta 1, do questionário aplicado em 2019.

A primeira pergunta foi "Participar do projeto "Formação Continuada de professores de Matemática" na UPF foi relevante? Caso tenha sido, explique como você percebe essa relevância."

Nas respostas, verificou-se que todos os professores indicaram que perceberam a relevância, destacando aspectos relacionados à proposta de formação continuada por meio dos pressupostos da investigação-ação. Apareceram indicativos tais como: a aprendizagem por meio do diálogo, da reflexão e da troca de saberes/experiências; o aprofundamento dos conceitos; o planejamento de aulas com objetivos claros tendo em vista a aprendizagem em matemática. Essas percepções podem ser percebidas no registro escrito de suas respostas: "[...] Formação continuada é isso, experimentar, avaliar, rever." (P2.1.2019) ou "Aprendi muitas coisas, conceitos que havia aprendido superficialmente durante minha atuação através da minha prática" (P2.1.2020) ou ainda: "[...] é fundamental para a evolução profissional docente, uma vez que, a escola é o espaço de atuação deste professor e a formação continuada é o espaço que ele tem para discutir e refletir sobre seu próprio fazer em sala de aula, "Práxis". A formação continuada proporciona ao professor aprender continuamente, avaliar $e$ aprimorar suas práticas docentes." (P4.1. 2019)

Essas percepções corroboram com aspectos da investigação-ação apresentados por Molina (2007, p. 13):

A atuação docente pode ser bem mais qualificada quando emparelha a ação com a reflexão sobre essa ação. Nesse sentido os processos de pesquisa/ação/investigação-ação são direcionados a constituição de um profissional que transforma seu trabalho em pesquisa. A consequência disso é maior autonomia, valorização profissional, criação e experimentação do vivido.

Ele também surge como uma alternativa para construção de novas formas de entendimento dos processos escolares a partir daqueles que atuam dentro da escola.

Os professores também destacaram como relevante o aspecto reflexivo e colaborativo na construção das propostas didáticas e, também, o modo como essa abordagem pela investigação-ação favoreceu seus modos de repensar os planejamentos de aulas: "[...] As discussões e debates sobre os temas, são sempre de muita relevância e me fazem pensar sobre minha prática de em sala de aula. A construção das sequências é sempre feita com muitas mãos, o que faz o trabalho mais enriquecedor e produtivo." (P5.1.2020) ou, ainda: "[...] Repensei meus métodos de ensino, aprendi com as experiências dos colegas e mudei o olhar que eu tinha para ensinar determinados conteúdos." (P6.1.2020).

As percepções apresentadas pelos professores nos dois anos confirmam a importância da ação coletiva e colaborativa da proposta. Esses indicativos corroboram com o 
que destacam os autores Mizukami et al. (2002, p. 43) sobre a colaboração nos processos formativos:

Os desafios devem ser vencidos coletivamente, com cada participante do processo educativo apoiando os colegas e apoiando-se neles. Nesse processo, cada um oferece o que sabe, e estando aberto para ouvir e analisar posições diferentes das suas, adquire outras formas de ver o mundo, de se ver nele e de compreender seu papel no exercício profissional.

Uma professora destacou a importância da cooperação e da socialização de saberes, que ocorreu por meio dessa ação extensionista na comunidade, tendo em vista a qualificação docente, propiciada pelo processo formativo vivenciado. Segundo a professora ela pensa ser relevante: "A cooperação entre a educação básica e a universitária. Minha prática também teve mudanças nestes dois anos." (P2.1.2020). Essa percepção indica que os projetos de extensão são meios que permitem aproximações entre a Universidade e a Comunidade na qual está inserida.

Essa percepção sobre a importância das ações extensionistas na comunidade corrobora com as conclusões de Souza et.al. (2018, p.44):

[...] pôde-se compreender a extensão universitária como um dos 'tripés' da Universidade brasileira, sendo a prática extensionista uma oportunidade de iniciar uma relação entre universidade e sociedade, sendo que a partir de tais ações será possível tornar real a educação transformadora que visa ir além dos limites físicos da universidade, alcançando mudança em toda comunidade através dos sujeitos que passam pelas transformações provenientes do conhecimento.

Outra professora participante do projeto, que além de atuar como professora no ensino médio, também faz parte de um programa de doutoramento, afirmou que a sua participação no projeto foi relevante, pois, além possibilitar a qualificação dos seus modos de planejamento de aulas, também propiciou momentos de reflexão e de formação tão significativos que inclusive a levaram refletir e a redefinir seu tema de doutoramento. Segundo ela: "[...] pude repensar e redirecionar meu projeto para o doutorado. Além disso, pensar sequencias didáticas de maneira colaborativa trouxe mais qualidade para o meu próprio planejamento de aulas." (P7.1.2020)

Em relação à segunda pergunta: "Quais aspectos você entende que foram positivos ou negativos", a qual foi respondida em 2019 e 2020, a maioria das percepções dos professores se referiram a aspectos positivos percebidos. Houve apenas duas manifestações sobre aspectos negativos.

Analisando todas as repostas, nos dois anos, foi possível perceber que o aspecto positivo mais citado, foi o fato da proposta ter sido oferecida por meio de encontros formativos dialógicos e reflexivos, nos quais ocorriam discussões, troca de experiências e de conhecimentos, teóricos ou práticos, que possibilitaram os planejamentos e reflexões sobre as ações propostas. Como exemplos: "[...] as elaborações das aulas eram maravilhosas, porque no debate de ideias surgiam sugestões que deram muito certo colocando em prática em sala de aula." (P3.2.2019); "[...] Momentos de leitura, discussão e reflexão. [...]" (P4.2.2019); "[...] oportunidade de refletir sobre minhas práticas de forma constante [...]" (P1.2.2020); "[...] trocas de ideias." (P2.2.2020); "[...] muitos debates e conversas que 
considero muito importantes para o professor nos tempos atuais." (P5.2.2020) ou "As discussões com o grupo [...]" (P7.2.2020).

O segundo aspecto positivo mais citado pelos professores participantes foi o caráter colaborativo, presente em todos os momentos do processo. Como exemplos: "[...] a grande contribuição por parte dos professores do curso de matemática da UPF [...]" (P1.2.2019); "[...] - Planejamento coletivo de uma proposta de intervenção na sala de aula." (P4.2.2019); "[...] o compartilhamento de ideias e ações-exemplos que deram certo e a possibilidade de ensinar matemática de uma forma muito mais prazerosa para mim." (P1.2.2020); "Colaboração [...]" (P2.2.2020) ou, ainda: "[...] a elaboração de uma sequência didática abordando o conteúdo de maneira colaborativa foi o que mais gostei; [...]" (P7.2.2020)

Tanto em 2019, como em 2020, os professores indicaram espontaneamente que perceberam como positivos alguns aspectos que são próprios da metodologia da investigaçãoação, tais como: "[...] mudanças de metodologia reforçando a aprendizagem [...]" (P2.2.2019); "[...]- Avaliação do fazer próprio fazer em sala de aula. -Aplicação da proposta. (P4.2.2019); "Sequência didática. Acompanhamento dos acertos e erros." (P2.2.2020); "[...] Saí da minha zona de conforto e comecei a planejar melhor...[...]" (P6.2.2020) ou "[...] elaboração de uma sequência didática abordando o conteúdo de maneira colaborativa [...]" (P7.2.2020).

Alguns professores destacaram como positivo o fato de o processo formativo possibilitar mudanças de abordagens metodológicas as quais favoreceram a aprendizagem. Como exemplos: "As mudanças de metodologia reforçando a aprendizagem dos mesmos. Aquilo que não deu certo é outra forma para tentar de outra maneira. [...]" (P2.2.2019) ou "[...] o aprendizado de forma prática do estudo das frações, onde estratégias simples geraram o entendimento da maioria dos alunos, [...]" (P3.2.2019).

Outro aspecto positivo destacado foi o fato de os estudantes das escolas gostarem das propostas didáticas elaboradas. Como exemplos: "[...] o conteúdo e a forma abordada atraíram muito a atenção dos alunos que estão participando. [...]" (P6.2.2020). ou "Meus alunos adoraram, percebendo também que precisam estudar um pouco mais." (P2.2.2019). Nesses casos, como era esperado, a percepção dos professores se deve ao fato de serem usadas estratégias nas elaborações das intervenções didáticas que visavam a abordagem de conteúdos por meio de situações vinculadas aos seus conhecimentos prévios, realidades ou aos temas interdisciplinares, os quais visaram despertar seus interesses pela aprendizagem.

Também apareceu uma percepção como aspecto positivo relacionada às presenças dos acadêmicos durante as aulas, no sentido de que elas estimulavam as participações mais ativas dos estudantes das escolas, durante as aulas presenciais. Para esse professor: "[...] $a$ presença dos estudantes de Matemática gerava mais questionamento, [...]" (P3.2.2019)

No que tange a presença dos acadêmicos bolsistas extensionistas durante as aulas presenciais (nas quais as propostas eram aplicadas, e também no momento da realização das oficinas, ocorridas no âmbito das escolas), apenas um dos professores, no ano de 2019, a percebeu como um aspecto positivo. Ele indicou ter percebido o crescimento dos acadêmicos, que foi propiciado tanto pela observação da prática, ocorrida em sala de aula, bem como pela vivência de experiências com a aplicação das oficinas desenvolvidas para atendimento das turmas dos professores participantes do projeto. Para esse professor: "A ida dos acadêmicos nas escolas. Vendo a realidade de cada uma. O crescimento deles junto com os nossos alunos [...]" (P2.2.2019). Outro professor, nesse mesmo ano, apenas destacou como positivo a realização de "[...] Oficinas para os estudantes. [...]" (P4.2.2019), mas não justificou essa escolha. 
Tardif (2002), ao abordar sobre aspectos da formação de professores, destaca o saber docente como um "saber plural" salientando a importância de vivenciar a prática pedagógica no processo de formação inicial. Indica que os saberes experienciais exigem conhecimento teórico, habilidade, capacidade de interpretação e de improvisação e, além disso, propiciam segurança para futuramente escolher estratégias metodológicas mais adequadas à aprendizagem.

Nesse sentido, em 2019, conforme as percepções do professor P2, as ações formativas desenvolvidas por meio do projeto de extensão propiciaram aos bolsistas extensionistas participantes o contato com os saberes práticos necessários para a atuação docente em sala de aula. Isso possibilitou aprimoramento de suas formações iniciais em suas preparações como futuros professores de matemática das escolas.

Como em 2020 o projeto foi desenvolvido por meio de reuniões remotas e as aplicações das propostas didáticas ocorreram também de modo remoto, essas ações participativas dos bolsistas extensionistas, no âmbito da sala de aula, acabaram não ocorrendo. Nesse sentido, foi possível perceber que a pandemia da COVID-19 acabou prejudicando a formação inicial dos acadêmicos, prevista no projeto de extensão, pois eles não tiveram essa oportunidade de desenvolvimento dos saberes práticos.

Uma professora se lembrou e destacou como um aspecto positivo as leituras de artigos realizadas, bem como as trocas de conhecimentos sobre os usos das Tecnologias de Informação e Comunicação (TDIC) que ocorreram durante o processo. Destacou: "[...] as leituras e outras atividades, como testar e aprender a utilizar plataformas como o Kahoot foram importantes." (P7.2.2020).

Em relação à segunda pergunta, apenas dois aspectos foram percebidos como negativos. Um deles foi apresentado em 2019, que se referia à falta de tempo que o professor sentiu para experienciar diferentes abordagens para o ensino e a aprendizagem em matemática. Conforme ele: "[...] durante o processo, o tempo, às vezes, se torna curto para tentar ideias." (P1.2.2019). Nesse caso, essa percepção estava relacionada ao processo vivenciado em 2019 e, provavelmente, se deu pelo fato desse professor ter participado do grupo apenas no segundo semestre. Nesse caso, a proposta foi elaborada e aplicada quase que simultaneamente, o que certamente gerou essa percepção do aspecto negativo descrito. Em 2020, como sua participação foi desde o primeiro semestre, esse mesmo professor teve a oportunidade de participar primeiramente da elaboração de toda a proposta. Somente depois ela foi aplicada. Assim, em 2020, essa percepção não apareceu na sua resposta à mesma pergunta.

O outro aspecto negativo indicado se referiu ao fato da pandemia da COVID-19 ter diminuído as participações dos estudantes das aulas, o que não permitiu que esses participassem da experiência propiciada pela aplicação da proposta, elaborada pelo grupo. Segundo o professor, pelo fato da modalidade de ensino: "[...] ser de forma remota, perdemos vários alunos que poderiam ser alcançados com esse projeto. “(P6.2.2020).

Quanto às respostas à terceira pergunta "Existem sugestões para qualificar o processo? Quais?" verificou-se que houveram poucas sugestões, mas todas relevantes.

Uma das sugestões foi de manter o trabalho colaborativo pelo fato de o professor entender que esse gera bons resultados. Segundo o professor: "Pensando na qualificação de todo o processo, penso que o planejamento em grupo, como tem sido feito, gera bons resultados. [...]" (P1.3.2019) 
Também foi sugerido dar continuidade ao projeto de formação nos anos seguintes, para mais professores. Segundo a professora, para que "[...] mais professores sejam desafiados a participar e perceber que precisamos de formação continuada e de mudanças no nosso planejamento das aulas." (P3.3.2019).

Outra sugestão para qualificação foi que nos próximos anos fossem avaliados os impactos das ações no âmbito da escola. Conforme a percepção da professora: "[...] Seria interessante analisar e identificar quais foram os resultados obtidos com as intervenções nas escolas." (P4.3.2019).

Esse aspecto também é percebido pelos professores extensionistas, que atuam e participam das ações do projeto, como orientadores. Verifica-se que se dedica muito tempo ao planejamento e execução das propostas e que, devido ao fato de o projeto ocorrer no período de um ano, geralmente acontecem imprevistos e atrasos no planejamento, o que acaba prejudicando o tempo destinado às avaliações reflexivas das ações. Desse modo, as percepções e indicativos sobre resultados ficam prejudicados. De fato, essa é uma fragilidade da proposta que entendemos que precisa ser melhorada.

Ainda na terceira pergunta, verificou-se que as percepções em 2020 foram bem diferentes. Algumas respostas foram curtas e evasivas. Talvez isso tenha ocorrido em função do cansaço dos professores nesse tempo da pandemia da COVID-19. A maioria deu a entender que concordavam com a proposta e que não tinham nada a acrescentar. Por exemplo: "Para mim, o processo acontece de uma forma muito orgânica a partir de conversas, vamos organizando as ações." (P1.3.2020) ou "Acredito que dessa forma está bom..." (P6.3.2020).

Uma reposta que surgiu numa perspectiva diferente foi a percepção de que poderíamos e que já estávamos aperfeiçoando o processo formativo produzindo vídeos explicativos, relacionados as sequências didáticas propostas. Como exemplo: "Neste momento já estamos aperfeiçoando com os vídeos explicativos." (P2.3.2020). Destaca-se que esse professor participou dos dois anos consecutivos e que ele percebeu essa mudança nos planejamentos propostos ao longo de 2020, a qual entendeu como aperfeiçoamento, que no ano anterior não havia.

Com a mudança do ensino presencial para o ensino remoto houve a necessidade de mudanças/adequações nos planejamentos de aulas por parte dos professores. Isso nos fez refletir e mudar abordagens na elaboração das propostas didáticas, o que, no ano de 2019, sequer havia sido cogitado, tais como a produção de videoaulas para disponibilização aos estudantes.

Também houve uma percepção de uma professora que destacou a necessidade de as reuniões serem mais breves no próximo ano, em 2021, caso continuem a serem realizadas remotamente. Na percepção da professora: "Se as reuniões continuarem de forma remota, talvez fosse interessante fazer uma enquete com os participantes, para saber qual o tempo ideal das reuniões semanais. Apesar das discussões serem sempre interessantes, reuniões longas são cansativas." (P7.3.2020). Essa percepção também revela esse cansaço físico, mental e emocional que todos os professores estão sentindo, frente à necessidade intensa de usos dos recursos tecnológicos digitais para o exercício da docência. A professora destaca que apesar de ser interessante, sente-se cansada com o fato das reuniões serem longas, o que é um indicativo que deve ser considerado em planejamentos futuros, caso se continue com a proposta remotamente.

Ao serem questionados sobre a pergunta: "As mudanças no ensino $e$ na aprendizagem da matemática em tempos da pandemia da COVID-19 e a necessidade de 
adaptação ao ensino remoto influenciaram as ações e objetivos do projeto? De que modo?", dentre os cinco respondentes, apenas três afirmaram que o objetivo do projeto se manteve. Por exemplo, um professor afirmou: "[...] sua qualidade e objetivo se manteve. Com a Pandemia ajudou e promoveu debates sobre a educação básica, auxiliando diretamente o professor em sala de aula, suas angustias e preocupações, bem como materiais que pudessem ajudá-los." (P5.4.2020).

Além disso todos indicaram que perceberam mudanças nas ações e citaram diferentes perspectivas.

Um deles citou que a realização de reuniões foi facilitada, pois passaram a ser realizadas por meio de encontros online, no Google Meet. No entanto, indicou que ainda sente preferência pelos encontros presenciais. Conforme o professor: "[...] nos encontrarmos de forma remota, [...] parece que simplificou a logística do projeto. Eu mesmo, se não fosse assim, não teria tempo durante o dia para participar. Mesmo assim, ainda sinto falta dos encontros presenciais." (P1.4.2020)

Em relação às mudanças nos planejamentos das ações, apareceram as percepções sobre a necessidade de ajustar as propostas tendo em vista às exigências que se apresentaram aos professores devido à pandemia da COVID-19.

Uma delas se referiu a mudança nas elaborações das ações a serem realizadas no ensino escolar, de modo que considerassem o ponto de vista dos estudantes, tendo em vista facilitar suas compreensões. Como exemplo: "[...] Tivemos que nos colocar no lugar do aluno para que ele pudesse entender o que estamos propondo. E ainda estamos no processo de fazer remotamente, $[. .$.$] ]" (P2.4.2020).$

Também apareceu a percepção de que foi necessário ajustar o planejamento das ações a serem aplicadas na escola, de modo que pudessem ser realizadas no contexto do ensino remoto. Conforme as percepções de duas professoras: "As ações foram alteradas para acompanhar o processo escolar, a que fomos surpreendidos durante esse ano. [...]" (P7.4.2020) ou "[...] muitos alunos ainda não conseguem acessar as mídias." (P2.4.2020).

As percepções dos professores remetem as dificuldades pelas quais todos os professores e estudantes passaram nessa época da pandemia da COVID-19. Todos foram surpreendidos por uma situação inusitada e tiveram que encontrar soluções rápidas para os diversos problemas que apareceram.

Além disso, relatos realizados durante as reuniões formativas do grupo, indicaram que os participantes percebiam que havia falta de conhecimento ou de experiência de muitos professores sobre usos de recursos tecnológicos digitais específicos para o ensino e a aprendizagem em matemática, sendo que esses foram grandes empecilhos para os docentes nesse período. Assim, houve a necessidade da busca pelo conhecimento sobre o uso adequado de tais recursos e também a necessidade de aquisição de equipamentos adequados, tais como computadores, mesas digitalizadoras ou webcams que os possibilitassem a comunicação virtual com seus estudantes.

Nesse aspecto, verificou-se que a participação dos professores nas reuniões no projeto de formação continuada no período da pandemia da COVID-19, os possibilitou aprenderem colaborativamente e a socializarem conhecimentos sobre diferentes possibilidades de usos de diversos recursos tecnológicos disponíveis, o que certamente contribuiu positivamente com suas formações nesse período.

Uma mudança significativa nas ações do projeto, percebida por uma das professoras participantes nessa modalidade de ensino, foi o fato dos bolsistas extensionistas não poderem 
estar presentes no contexto da sala de aula, de modo a observar a prática docente e aprender com essa experiência. Conforme a professora: "[...] Desta forma, ao invés de termos bolsistas na sala de aula, eles participaram de todo o planejamento das ações, e isso foi bom." (P7.4.2020).

O que se verifica é que a professora percebeu que essa mudança teve esse aspecto negativo, mas, por outro lado, indicou o aspecto positivo relacionado à participação mais frequente dos acadêmicos nos encontros de planejamento das ações.

Com mudança para o contexto do ensino remoto, no que tange à contribuição com à formação inicial, também propiciada por meio da participação dos discentes no projeto de formação, percebe-se que essa modalidade impossibilitou o desenvolvimento dos saberes práticos, advindos com a observação e a experiência, os quais são vivenciados em sala de aula presencial.

Conforme Tardif (2002), como há a necessidade da complementação dos saberes práticos e teóricos para o exercício pleno da profissão docente, verifica-se que, ao serem retomadas as ações do projeto de formação de professores no contexto presencial, esse aspecto negativo deve ser contornado. As ações devem ser promovidas de tal modo que os acadêmicos possam participar efetivamente nos dois momentos de formação, tendo em vista estimular tanto o desenvolvimento de conhecimentos teóricos, como o de conhecimentos práticos.

Finalmente, ao responderem a pergunta "De modo geral, como você percebe as experiências e sentidos da "não presença" no ensino e na aprendizagem da matemática em tempos da pandemia da COVID-19?" foi possível perceber de modo mais abrangente que foram muitas percepções sobre a "não-presença" dos professores e dos estudantes nesse contexto.

Uma delas, que chama a atenção, se refere justamente ao desânimo que o professor sente pela "não-presença", pela falta do contato visual, pela falta de interação nos processos de ensino e de aprendizagem em matemática. Conforme a percepção do professor: "É complicado. Não ver o aluno e seu rosto é o que mais me desanima diariamente. Muitas turmas deixam sempre as câmeras desligadas ou participam pouco das aulas, o que faz com que todo o nosso trabalho feito, às vezes pareça não ter sentido. Mas sei que isso não depende só de mim e sim, dos meus alunos e seu modo de pensar e avaliar quais são as prioridades principais de sua vida." (P1.5.2020).

Uma percepção comum à dois professores participantes foi o fato de entenderem que o processo de aprendizagem em matemática foi muito prejudicado nesse ano de 2020 . Apesar de se sentirem comprometidos com a educação, apresentam preocupações com a retomada do processo, pois entendem que haverá muitos prejuízos para os estudantes das escolas, apesar dos esforços e comprometimentos dos professores. Conforme as percepções: "Vai ser muito impactante, quando e se voltarmos. Muitos alunos não conseguem entender o básico. Muitas vezes, nos sentimos frustrados por não ter o quórum almejado. Mas acreditamos que o caminho ainda é a educação. Neste momento, terá muitas lacunas. [...]" (P2.5.2020) ou ainda: "O ensino e a aprendizagem foram muito comprometidos. Aprendizagem em minha visão não há como comprovar ou dizer que foi eficaz. Nós professores demos o nosso máximo e nos reinventamos para que a aprendizagem acontecesse, mas dependeu muito do esforço de cada estudante também." (P5.5.2020).

As percepções em relação ao ensino e à aprendizagem são destacadas por duas professoras, que se referem ao processo de aprimoramento/adequação dos professores 
frente às necessidades emergentes com o ensino remoto, no período da pandemia da COVID19, sendo que uma delas destaca a importância da mediação do professor nesse processo de aprendizagem. Conforme as professoras: "[...] Quanto ao ensino de matemática, tem sido bem desafiador, pois realmente tivemos que nos reinventar e aprender muitas coisas que talvez já pensei que não iria precisar." (P6.5.2020) ou, ainda, "O papel do professor tem destaque nesse processo, pois fica responsável por "dar um jeito" de estudantes aprenderem mesmo não estando em sala de aula. [...]" (P7.5.2020).

Quanto às dificuldades relacionadas à aprendizagem dos estudantes, uma professora indica várias dificuldades e destaca a importância da figura do professor que mesmo estando distante, se faz presente, buscando alternativas para promover a aprendizagem dos estudantes. Segundo a professora: "[...] Muitos fatores vão contra esse processo de aprender, como falta de conexão com a internet, falta de recursos para gravar boas aulas, falta de interesse de alunos e familiares. Mesmo assim, professores de todo o mundo tem feito seu melhor para promover seus componentes em meio a esse caos instalado no sistema." (P7.5.2020)

\section{Considerações finais}

A análise realizada, no presente artigo, sobre percepções docentes, em participações de um projeto de formação continuada de professores de matemática, realizadas em 2019 e em 2020, em tempos da pandemia da COVID-19, permitiram concluir que apesar da necessidade de mudança/adequação para que a proposta continuasse a ser oferecida na modalidade remota, os objetivos propostos e atingidos não mudaram. Isso pode ser concluído conforme os indicativos apresentados sobre as percepções dos professores, ao serem questionados sobre à relevância e sobre aspectos positivos do projeto em suas formações profissionais.

Conforme constatado os professores perceberam, nos dois anos, importantes aspectos dos pressupostos da Investigação-Ação, tais como: a aprendizagem por meio do diálogo, da reflexão e da troca de saberes/experiências; o aspecto reflexivo e colaborativo na construção das ações ou propostas didáticas e, também, o modo como essa abordagem favoreceu seus modos de repensar os planejamentos de aulas.

Assim, ao término desse trabalho, nos dois anos, é possível concluir que a proposta de formação, segundo os pressupostos da investigação-ação continuaram sendo viáveis, mesmo no contexto do ensino e da aprendizagem remota. Verificou-se que, no grupo, houve: (i) receptividade à experimentação e ao desenvolvimento profissional; (ii) o desenvolvimento do trabalho reflexivo em equipes, de acordo com suas necessidades e interesses provenientes do contexto natural do trabalho da escola; e (iii) o desejo de inovação e de melhorias em suas próprias práticas; os quais são os três fatores que podem promover o desenvolvimento profissional, segundo Saraiva e Ponte (2003).

Uma percepção positiva e interessante sobre medidas de distanciamento, em razão da pandemia da COVID-19, foi destacada por um docente no sentido de que a "não-presença" favoreceu a realização dos encontros (online, por meio do Google Meet) o que facilitou a participação pelo fato de não ser necessário disponibilizar tempo para o deslocamento até a universidade. Destaca-se, inclusive, que em 2020 houve uma maior participação de professores no processo formativo, devido a esse aspecto.

Comparando as ações nos dois anos, devido à imposição da modalidade remota no ensino escolar, nesse período da pandemia da COVID-19, uma mudança importante foi a 
impossibilidade do aprimoramento do conhecimento prático aos bolsistas extensionistas (acadêmicos do curso de licenciatura em matemática) o qual ocorreria por meio de experiencias vivenciadas no contexto da sala de aula. No entanto, pelas percepções dos professores verifica-se que, nesse ano, apesar de ter esse aspecto negativo, o fato de os acadêmicos poderem estar presentes nos encontros, nos quais ocorreram as discussões e reflexões, as quais conduziram a elaboração da ação, favoreceu o desenvolvimento de conhecimentos teóricos, o que foi um aspecto positivo para a formação inicial dos bolsistas extensionistas, os quais em 2019 não tinham tido essa oportunidade, pelo fato de muitas vezes estarem participando de oficinas oferecidas aos estudantes das turmas dos professores que participavam dos processos formativos.

Também apareceu o indicativo da percepção que essa proposta possibilitou uma aproximação entre a Universidade e a Educação Básica, tendo em vista a qualificação docente, propiciada pelo processo formativo vivenciado.

Além disso, foi possível perceber que a proposta de trabalho estimulou a integração entre ensino, pesquisa e extensão. As reflexões e a construção colaborativa de ações, pelos integrantes do grupo, constituído por professores das escolas (dentre eles, professores formados, sendo que alguns eram estudantes de especialização ou de mestrado ou de doutorado), acadêmicos extensionistas (graduandos - professores em formação inicial) e por professores universitários, possibilitaram socializar e aprimorar o desenvolvimento de conhecimentos relacionados aos processos de ensino e de aprendizagem em matemática nos diferentes espaços e níveis de atuação de cada um.

Quanto às necessidades de mudanças/adequações metodológicas exigidas no período da pandemia da COVID-19, verificou-se nas percepções dos docentes que eles sentiram que o projeto os ajudou nesse processo de transição. Nós, autoras do presente artigo, como participantes do projeto, também percebemos que o grupo de professores constituído possibilitou que ocorresse o compartilhamento de saberes, não somente relacionados aos conhecimentos matemáticos e pedagógicos, os quais se objetivava trabalhar, mas também foram trocadas informações sobre possibilidades de abordagens alternativas com o uso de recursos tecnológicos digitais, como aplicativos ou uso de plataformas, que ajudaram a todos nessa transição.

Além disso, destaca-se que os participantes do grupo também se ajudaram, não só do ponto de vista profissional, mas também do ponto de vista emocional. Nos encontros eram realizados compartilhamentos de problemas e de angústias, que muitas vezes eram comuns entre nós, e por meio da escuta dialogada e da reflexão sobre as dificuldades encontradas, foi possível, na maioria das vezes, encontrar soluções para os problemas compartilhados.

As percepções dos professores indicam que apesar das dificuldades encontradas nesse processo de transição para o ensino remoto, percebem que os professores de matemática das escolas, nas quais trabalham, continuam comprometidos com o processo e que, apesar de muitos não conhecerem, ou não estarem habituados, a fazerem usos das TDIC no processo de ensino e de aprendizagem, eles passaram a usá-las, conforme foi possível. No caso dos professores participantes, verificou-se que o trabalho reflexivo, realizado em grupo colaborativo, ajudou a todos nesse sentido.

Há muitos anos, vários autores, tais como Borba e Penteado (2001); Kampff (2006), Kensky (2007); Lévy (1993) já indicavam essa necessidade de inserção das tecnologias digitais da escola, tendo em vista aproximar as realidades do ambiente escolar com a dos estudantes, pelo fato de viverem em meios permeados de tecnologias com as quais convivem e aprendem. 
Há 12 anos, D’Ambrósio (2008, p. 80) afirmava que:

A escola não se justifica pela apresentação de conhecimentos obsoletos e ultrapassados e muitas vezes morto, sobretudo ao se falar em ciência e tecnologia. Será essencial para a escola estimular a aquisição, a organização, a geração e a difusão do conhecimento vivo, integrado nos valores e expectativas da sociedade. Isso será impossível de se atingir sem a ampla utilização de tecnologia na educação. Informática e comunicação dominarão a tecnologia educativa do futuro.

A necessidade do distanciamento devido a pandemia da COVID-19 acelerou esse processo e, provavelmente, muitos professores fizeram uso dos recursos que tinham familiaridade ou que seriam mais acessíveis no momento, sem ter muito tempo para refletir sobre eles. No entanto, concorda-se com Kampf:

As tecnologias, [...] ampliam o potencial humano. Todos reconhecem o papel fundamental das instituições escolares no desenvolvimento intelectual, social e afetivo do indivíduo. [...] cabe à escola incorporar em seu trabalho, apoiado na oralidade e na escrita, outras formas de aprender, [...] com uma tecnologia cada vez mais avançada. Mais do que resistir, é preciso desvendála e, conscientemente fazer uso dela (KAMPFF, 2006, p. 11-12).

Assim, uma questão que identificamos ser relevante em investigações futuras seria mapear quais foram as tecnologias utilizadas, nesse período, e se, de fato, elas foram consideradas adequadas para promover a qualificação da aprendizagem em matemática.

\section{Referências}

ANDERSON, Gary; HERR, Kathryn. O docente-pesquisador: a investigação-ação como uma forma válida de geração de conhecimentos. Revista Interinstitucional Artes de Educar. Rio de Janeiro, v.02, n. 1, p.4-24, 2016.

BORBA, Marcelo de Carvalho; PENTEADO, Miriam Godoy. Informática e Educação Matemática. 1. ed. Belo Horizonte: Autêntica, 2001.

D’AMBROSIO, Ubiratan. Educação matemática da teoria à prática. 16.ed. Campinas/SP: Papirus, 2008.

KAMPFF, Adriana Justin Cerveira. Tecnologia da informática e comunicação na educação. Curitiba: IESDE Brasil S.A., 2006. 144 p.

KENSKY, Vani Moreira. Educação tecnologias: o novo ritmo da informação. Campinas: Papirus, 2007.

LÉVY, Pierre. As tecnologias da inteligência: o futuro do pensamento na era da informática. Rio de Janeiro: ed. 34, 1993.

MINAYO, Maria Cecília de Souza. O desafio da pesquisa social. In: MINAYO, Maria Cecília de Souza (Org). Pesquisa Social: Teoria, método e criatividade. 27. ed., Petrópolis, Rio de Janeiro: Vozes, 2008. p.9-30. 
MIZUKAMI, Maria da Graça Nicoletti, et al. Escola e Aprendizagem da docência: processos de investigação e formação. São Paulo: EdUFSCar, 2002.

MOLINA, Rinaldo. A pesquisa-ação/investigação-ação no Brasil: mapeamento da produção (19662002) e os indicadores internos da pesquisa-ação colaborativa. Orientador: Elza Garrido. 2007. 177 f. Tese (Doutorado em Educação) - Faculdade de Educação, Universidade de São Paulo, São Paulo, 2007. doi:10.11606/T.48.2007.tde-25072007-150643.

NÓVOA, Antônio. Firmar a posição como professor, afirmar a profissão docente. Cadernos de Pesquisa. v. 47, n. 166, p.1106-1133, 2017.

PONTE, João Pedro da. Da formação ao desenvolvimento profissional. In: ProfMat, 1998, Lisboa, Portugal. Actas. Lisboa: APM, 1998, p. 27-44

SARAIVA, Manuel; PONTE, João Pedro da. O trabalho colaborativo e o desenvolvimento profissional do professor de Matemática. Quadrante, Portugal: APM - Associação de Professores de Matemática, v. 12 , n. 2, p. 25-52, 2003.

SOUZA, Ruan Lion Costa de et al. Evidenciando a extensão e sua importância nas licenciaturas.

Vivências: Revista Eletrônica de Extensão da URI. v. 14, n. 27, p. 38-45, 2018.

TARDIF, Maurice. Saberes docentes e formação profissional. Petrópolis, RJ: Vozes, 2002.

\section{Agradecimentos}

Agradecemos aos professores da Educação Básica que participaram do Projeto de Extensão: "Formação Continuada de Professores de Matemática" (PFCPMat), da UPF, nesses dois anos, pois entendemos que, sem eles, não alcançaríamos às escolas como planejamos. Aos professores orientadores e aos bolsistas extensionistas, cujo trabalho pode ser percebido em cada etapa, do planejamento à execução das ações e análise dos resultados parciais. Por fim, à Universidade de Passo Fundo, por fomentar e oportunizar espaços de pesquisa e extensão de maneira a permitir o aprimoramento de nossas práticas por meio da elaboração de ações em grupos formativos, de forma reflexiva e colaborativa. 